\title{
O DIREITO DO CONSUMIDOR À INFORMAÇÃO E AS NANOTECNOLOGIAS: OS NOVOS HIPERVULNERÁ VEIS
}

\author{
Fábio Campelo Conrado de Holanda \\ Centro Universitário 7 de Setembro - UNI7, Ceará. \\ fabiodeholanda@yahoo.com.br \\ Maria Lúcia Falcão Nascimento \\ Centro Universitário 7 de Setembro - UNI7, Ceará. \\ mlf.01@uol.com.br
}

\begin{abstract}
RESUMO: O presente trabalho visa examinar o dever de informação do fornecedor frente aos riscos que os consumidores correm em contato com produtos desenvolvidos a partir de nanopartículas e analisar se os nanoconsumidores são hipervulneráveis, vinculados aos próprios consumos, ou se estariam diante de uma nova espécie de hipervulnerabilidade, vinculada a uma categoria ainda não especificada pela doutrina. Investiga a qualidade e a suficiência das informações passadas ao consumidor através do estudo do direito à informação (art. $6^{\circ}$, II, do CDC) como instrumento de capacitação do consumidor frente aos riscos do mercado de consumo e sua condição presumida de vulnerabilidade e a hipervulnerabilidade pelos riscos imprevisíveis do nanoconsumidor; a proteção à saúde e segurança; e a efetividade da política nacional de relações de consumo previstas no art. $4^{\circ}$ do CDC. Busca-se um conhecimento complexo por meio de informações em outras áreas das ciências humanas — tais como saúde, educação, engenharia, ciência e tecnologia - utilizando-se o método dedutivo e indutivo (com enfoque para a pesquisa bibliográfica assentada em referenciais teóricos nacionais e estrangeiros), de modo a concluir que, ante a ausência de informações claras e objetivas dos possíveis riscos à saúde e à segurança do consumidor de produtos industrializados a partir de nanopartículas, há infringência ao princípio constitucional de $4^{\mathrm{a}}$ dimensão e à previsão consumerista do direito à informação. Além disso, na ausência de esclarecimentos, informações e orientações dos órgãos integrantes do Sistema Nacional de Defesa do Consumidor (SNDC), o consumidor brasileiro encontra-se em situação de hipervulnerabilidade, que se insere em uma condição de fragilidade apriorística em face da imprevisibilidade dos riscos advindos do manejo da nanotecnologia, próprios do ambiente societário pós-moderno.
\end{abstract}

PALAVRAS-CHAVE: Hipervulnerabilidade. Nanoconsumidor. Informações nanotecnológicas.

\section{Consumer law to information and nanotechnologies: the new hypervulnerables}

ABSTRACT: This paper aims to examine the supplier's duty to inform consumers about the risks that consumers are in contact with products developed from nanoparticles and to analyze if nanoconsumers are hypervulnerable, linked to their own consumption, or if they are facing a new kind of hypervulnerability, linked to a category not yet specified by the doctrine. It investigates the quality and sufficiency of information passed on to consumers through the study of the right to information (article 6, II, of the CDC) as a tool for empowering consumers in relation to consumer market risks and their presumed condition of vulnerability and hypervulnerability. the unpredictable risks of the nanoconsumer; health and safety protection; and the effectiveness of the national policy of consumer relations provided for in art. 4th of the CDC. Complex 
knowledge is sought through information in other areas of the humanities - such as health, education, engineering, science and technology - using the deductive and inductive method (focusing on bibliographic research based on national and international theoretical references). In order to conclude that, given the lack of clear and objective information on the possible risks to the health and safety of consumers of products manufactured from nanoparticles, the 4th dimension constitutional principle and the consumerist right to information. In addition, in the absence of clarifications, information and guidance from the members of the National Consumer Protection System (SNDC), the Brazilian consumer is in a situation of hypervulnerability, which is inserted in a condition of a priori fragility due to the unpredictability of risks arising from the management of nanotechnology, inherent to the postmodern societal environment.

KEYWORDS: Hypervulnerability. Nanoconsumer. Nanotechnological information.

\section{INTRODUÇÃO}

Quando se fala em nanotecnologia e relações de consumo, algumas indagações centrais vêm à tona: estaria o destinatário final destes produtos suficientemente informado de suas consequências? Em que se diferencia o consumidor em geral daquele que consome bens contendo nanotecnologias (existe uma agudização de sua vulnerabilidade apriorística)? Qual o fundamento teórico para abalizar uma eventual responsabilização do fornecedor por danos imprevistos causados ao nanoconsumidor?

Imagine-se a quotidiana situação de um consumidor qualquer que entra em um salão de beleza e solicita o serviço de hidratação capilar; outro consumidor, em uma clínica de estética, pede uma massagem redutora de medidas; outro, compra em uma loja um produto qualquer e leva para casa. Estes fatos simples tem uma indissociável relação com a chamada "pós-modernidade". Entre uma prestação de serviço e outra, entre uma venda de produto e outra, milhões de pessoas consomem produtos e não conhecem como são produzidos ou fabricados. Entre muitos dos produtos postos no mercado, alguns já são elaborados com base em tecnologias mais avançadas, como a nanotecnologia.

Começando na arquitetura, o pós-modernismo permeou todos os setores da sociedade. Em sua indeterminação conceitual e na provisoriedade de sua conformação, a expressão pósmodernidade foi ganhando força e cada vez mais espaço nos escritos acadêmicos, o que faz dela o nome para um estado de coisas de cuja consciência ainda estão se retirando análises (BITTAR, 2014, 116-117).

A propósito, a nanotecnologia é a ciência que estuda a matéria e lida com a sua transformação em nanoescala de 1 a 100 nanômetros. Melhor explicando, a escala nanométrica é a bilionésima parte de um metro. Também chamada de escala atômica, as partículas são tão minúsculas (um décimo da largura de um fio de cabelo) que somente podem ser vistas por meio de um microscópio.

Não somente na tecnologia, mas em várias outras áreas da ciência em geral, as partículas nanométricas, ou nanopartículas, têm sido utilizadas em benefício da humanidade — na área da medicina, em prevenção e cura de várias doenças, tratamentos de câncer e de reabilitação por meio de equipamentos cada vez mais sofisticados; produtos farmacêuticos com melhor atuação no combate de doenças; na cosmética, na fabricação de produtos rejuvenescedores; na informática, na fabricação de eletroeletrônicos menores e mais leves; na indústria têxtil e de calçados, na fabricação de roupas inteligentes (apropriadas para uso nas UTI's, por exemplo); e na engenharia, na fabricação de argamassa expansiva (considerada mais ecológica). A propósito desse derradeiro exemplo, parte da doutrina entende que: 


\begin{abstract}
A argamassa expansiva é um agente demolidor não explosivo, em pó, cujo componente majoritário é a cal virgem. Em contato com água, iniciam-se reações de hidratação, com aumento de volume durante o progresso dessas reações, promovendo, quando em confinamento, grandes pressões sobre as paredes confinantes, as quais chegam aproximadamente a $78 \mathrm{MPa}$. Essas tensões geram fissuras (no meio demolir), cuja magnitude e direção dependem do balanço de esforços atuantes no referido meio. O campo de ação da argamassa é praticamente ilimitado, servindo para romper, cortar e demolir rochas, concreto, e concreto armado. É um produto altamente ecológico, pois além de não ser explosivo, não produz gases nem resíduos nocivos (PAULO; CAETANO; GERALDO, 2015).
\end{abstract}

$\mathrm{O}$ avanço tecnológico visando à modificação da matéria poderá contribuir, ainda, com a redução da utilização indiscriminada da matéria-prima retirada da natureza para a produção de bens. O que se espera da nanotecnologia é proporcionar um menor uso de matérias-primas e energia para a realização dos mesmos processos e produtos já conhecidos, racionalizando a exploração dos diversos ecossistemas naturais.

Como visto, a contribuição da nanotecnologia para a ciência é imensurável, contudo, ainda são uma incógnita os eventuais malefícios que as nanopartículas possam vir a causar à natureza ao ser humano consumidor. Segundo noticiou a revista Época em matéria publicada em 28 de agosto de 2007, na página de ciência e tecnologia, naquela época o mercado de consumo já contava com mais de quinhentos produtos corriqueiros fabricados com base na nanotecnologia - como shampoo, protetor solar, chip de computador, dentre outros - e a estimativa era de que até 2014 o comércio movimentaria US\$ 1,2 trilhão (FREITAS, 2007).

Por serem menores do que os glóbulos vermelhos, conforme exposto no início do texto, as nanopartículas soltas na atmosfera tem o condão de atravessar a pele, além de serem respiradas e engolidas por meio da água ou dos alimentos. Em que pese tais constatações, ainda não há estudo científico seguro quanto aos efeitos da acumulação dessas partículas no organismo humano, na fauna e na flora.

A propósito dos riscos do desenvolvimento previstos no Código de Defesa do Consumidor (CDC) e a respectiva responsabilidade do fornecedor por defeitos não detectáveis pelo estado dos conhecimentos científicos e técnicos, a doutrina pontua que a existência de defeito não é suficiente para a caracterização dos riscos do desenvolvimento, esclarecendo que "somente há se falar em riscos de desenvolvimento se o defeito for incognoscível no momento da colocação do produto no mercado ou da prestação do serviço" (REINIG, 2019, p. 357).

Voltando ao exemplo inicial, quando o consumidor busca o salão de beleza com o objetivo de utilizar um produto cosmético, ele é capaz de saber as informações constantes no rótulo, a composição química, para o que serve e o modo de usar, mas não sabe, ainda que "devidamente informados", o que significa ter sido o produto desenvolvido à base de nanotecnologia, quais os efeitos do produto ao manipulá-lo com suas próprias mãos, eventuais riscos ou o que acontecerá com o meio ambiente, porque nem mesmo a ciência tem certeza dos resultados.

Na cadeia de produção se encontram (conforme artigo $3^{\circ}$ da Lei 8.078/90), tanto a pessoa física como a jurídica, seja ela pública ou privada, nacional ou estrangeira, bem como os entes despersonalizados, que desenvolvem atividades de produção, montagem, criação, construção, transformação, importação, distribuição ou comercialização de produtos ou prestação de serviços. Porém, são os fabricantes que adquirem as nanotecnologias desenvolvidas pelos cientistas nas grandes universidades e laboratórios. Nesse contexto, será que todos estes atores são alertados quanto aos possíveis riscos? 
O direito do consumidor é um direito constitucionalmente protegido em favor do consumidor. É direito básico do consumidor, nos termos do artigo $6^{\circ}$, inciso III, do CDC, "a informação adequada e clara sobre os diferentes produtos e serviços, com especificação correta de quantidade, características, composição, qualidade, tributos incidentes e preço, bem como os riscos que apresentem" (BRASIL, 1990). Os riscos em relação ao uso de nanopartículas ainda são indefinidos. Assim, como os fornecedores podem cumprir o dever de informação em sua plenitude? Estaria o consumidor imiscuído em uma nova espécie de hipervulnerabilidade? Por mais bem elaborada que seja a informação, será possível ao consumidor homem médio extrair dela o devido entendimento dos eventuais riscos que corre pela utilização de produtos ou serviços atomicamente alterados?

Importa, então, investigar a qualidade das informações passadas ao consumidor brasileiro pelos fornecedores e órgãos do Sistema Nacional de Defesa do Consumidor, que se encontra em situação de hipervulnerabilidade técnica, ante o desconhecimento da tecnologia envolvida na fabricação dos produtos a que têm acesso.

Metodologicamente, utilizando-se do processo sistemático dedutivo e indutivo, a pesquisa será construída fundamentalmente no aprofundamento bibliográfico com base na doutrina nacional e estrangeira, não apenas direcionada à temática consumerista, mas necessariamente afeta ao tema da complexidade e da ciência pós-moderna. O método dedutivo é aquele cuja pesquisa parte do geral para o individual, como é o caso das ciências jurídicas em geral. Já o indutivo é o método segundo o qual o pesquisador parte de situações individuais para o geral, que é o que também se apresenta como o mais adequado à estruturação de parte da pesquisa quando se faz a abordagem principiológica, e o que se fará através dos julgamentos registrados nos bancos de dados do Superior Tribunal de Justiça. Tais métodos se nos apresentam como os mais adequados para o desenvolvimento do tema.

O objetivo geral da pesquisa é apresentar ao leitor o problema geral da vulnerabilidade do consumidor frente ao consumo de nanopartículas e a defecção informacional a que se sujeita na sociedade contemporânea. $\mathrm{O}$ objetivo específico da pesquisa é verificar em que medida os fornecedores de bens de consumo podem ser responsabilizados por danos causados à saúde do consumidor, inclusive com arrimo na opinião de autores estrangeiros, dada a repercussão dessa questão da nanotecnologia para além de nossas fronteiras.

Para tanto, serão desenvolvidos nos seguintes tópicos: primeiramente, será estudada a importância do direito à informação como instrumento de capacitação do consumidor frente aos riscos do mercado de consumo, seguindo-se de uma análise acerca da vulnerabilidade presumida e da hipervulnerabilidade pelos riscos imprevisíveis do nanoconsumidor. Por último, será examinada a proteção à saúde e à segurança e a efetividade da política nacional de relações de consumo previstos no artigo $4^{\circ}$ do CDC.

A realização do presente estudo demanda conhecimento complexo em outras áreas das ciências humanas, tanto que a visitação a sites oficiais relacionados a saúde, educação, engenharia, ciência e tecnologia foi o ponto de partida para o desenvolvimento da pesquisa, no intuito de buscar informações prós e contras os meios científicos utilizados para o crescimento da tecnologia. As críticas que o texto enfrentar serão suficientes contribuições ao tratamento de tema tão caro para quem, como o autor, prestigia o estudo das relações consumeristas na contemporaneidade. 


\section{DIREITO À INFORMAÇÃO COMO INSTRUMENTO DE CAPACITA- ÇÃO DO CONSUMIDOR}

Na década de 1960, o então presidente americano John Fitzgerald Kennedy afirmou em discurso que todos somos consumidores. Por intermédio de comunicações junto ao Congresso americano, estabeleceram-se os critérios de maior relevância sobre a proteção dos direitos do consumidor (entre eles, os bens e serviços colocados no mercado, os quais deveriam ser sadios e seguros para o uso, apresentados de uma maneira que permitisse ao consumidor fazer uma boa escolha, garantindo, além disso, o seu direito de ser informado sobre condições e serviços). Em 1973, a 29a Sessão da Comissão de Direitos Humanos da Organização das Nações Unidas (ONU), ocorrida em Genebra, ratificou o princípio do direito à informação, definindo-o como fundamental ao consumidor.

Em 1985 as Nações Unidas estabeleceram, pela primeira vez, através da Resolução n. ${ }^{\circ}$ 39, normas, princípios e objetivos destinados a assegurar as garantias legais aos direitos dos consumidores (SANTANA, 2014, p.53-64). A referida norma estabeleceu os primeiros direitos basilares dos consumidores, conhecidos em escala mundial, prevendo princípios que deveriam ser considerados pelos países membros, tais como a proteção do consumidor quanto a prejuízos à sua saúde e segurança e fomento e proteção dos interesses econômicos dos consumidores.

Na sociedade do consumo, o direito à informação é basilar ao consumidor, que terá nele o alicerce para o consumo crítico, livre e sustentável. A informação se torna um elemento na capacitação dos consumidores para o exercício da cidadania e do consumo consciente. Sobre a origem da informação no âmbito das legislações civis e com reflexos nas relações consumeristas, circunstanciada é a lição de Schier (2006, p. 34) ao esclarecer que o Código Civil também traz intrinsecamente o direito à informação em seu princípio norteador: o da boa-fé objetiva, o qual já havia mencionado no Código Comercial de 1850, quando em seu art. 131 referenciava a boafé quando da interpretação das cláusulas do contrato, as quais deveriam ser conforme a boa-fé.

No Brasil, consta originalmente no artigo $5^{\circ}$, inciso XXXII, da Constituição Federal de 1988 (BRASIL,1988) a previsão da proteção do consumidor. Para a garantia da efetividade desses direitos, trouxe o Código de Defesa do Consumidor (CDC) (BRASIL,1990) um sistema principiológico com normas de interesse público e que, sobretudo, reconhece no inciso I do art. $4 .^{\circ}$ a vulnerabilidade do consumidor como um um princípio a ser atendido. A vulnerabilidade do consumidor existe também em função do seu déficit de informação quanto ao produto ou serviço.

Tratando dos ciclos da sociedade de consumo, Lipovetsky (2015, p. 48) pontua que o cenário atual se caracteriza pelo enfoque com as despesas de saúde, o "reino do homo medicus". Segundo o autor francês, "é a máquina tecnocientífica que tem as cartas na mão e que conduz as operações excluindo o paciente. A eficácia médica alarga o poder do homem sobre a sua vida, mas cria um consumidor sem poder". Neste sentido, tratando sobre a expansão da indústria cosmética no Peru, Vasquez; Granados e Llerena (2015, p. 109) esclarece que:

La medicalización de la vida es un proceso que se puede rastrear, según Foucault
(1977), desde la época moderna. Durante el siglo XVIII, el cuerpo, la salud y la en-
fermedad, fueron monopolizados por el tratamiento médico, legitimado por el poder
del Estado, el mercado y la sociedad. En la actualidad, este proceso se reviste de
factores nuevos y distintos, como la globalización, la cultura del consumo, la idea de
igualar la salud con la belleza, etc. Es en este contexto, en el que los consumidores
tienen una mayor agencia, en el que la industria cosmética incursiona en la investi-
gación en nanotecnología para la elaboración de nuevos productos.

Com o progresso e o desenvolvimento do consumo de massas, observou-se a necessidade de melhor transparência e proteção mais eficiente nas relações de consumo. A necessidade de 
informação mais clara e objetiva faz toda a diferença na hora da realização dos negócios jurídicos porque dá ao consumidor a liberdade de optar pela oferta que melhor lhe aprouver. O dever de informar é um reflexo do princípio da transparência e é mais do que um simples elemento formal, afeta a essência do negócio, pois a informação repassada ou requerida integra o conteúdo do contrato e se houver falha na informação, esta representa a falha na qualidade do produto ou serviço oferecido ou um defeito.

Ocorre que transparência e previsibilidade informacional (premissas que devem guiar a política nacional das relações de consumo) são conceitos incompatíveis com os pressupostos da ciência pós-moderna, complexa. Enquanto na ciência clássica prevalecia o paradigma da razão absoluta, por conduto de uma lógica formal e epistemológico com viés mecanicista do mundo, a ciência contemporânea se desenvolve com um pressuposto epistemológico transdisciplinar, admitindo um universo de probabilidades, incertezas, múltiplas verdades e explicações apenas provisórias.

Na esteira do pensamento de Ulrick Beck (2011), tais riscos têm aspectos positivos (como o aprimoramento da democracia, do multiculturalismo e da tolerância) e negativos (como a crise do Estado, a flexibilização das garantias do trabalho, o terrorismo etc.). Quando os riscos passam a ser globais e não-controláveis, tem-se que os danos não são mais delimitáveis, tornando-se, por vezes, irreparáveis; as medidas preventivas dos piores acidentes são mitigadas; e os acidentes não tem um encadeamento linear, tendo começo mas, com desdobramentos autônomos, "sem final".

No julgamento da REsp 1.358.615-SP, o Ministro Luis Felipe Salomão, da quarta Turma do STJ, diz que a informação inadequada do fornecedor gera defeito extrínseco, pontuando que o fornecedor do produto responderá pelos danos causados ao consumidor na hipótese em que conste, na embalagem do produto, apenas pequena e discreta anotação de que deve ser evitado. Segundo o tribunal, tem-se por configurado defeito extrínseco do produto, qual seja, a inadequada informação na embalagem do produto, porquanto a informação deve "ser prestada de forma inequívoca, ostensiva e de fácil compreensão, principalmente no tocante às situações de perigo, haja vista que se trata de direito básico do consumidor (artigo $6^{\circ}$, inciso III, do CDC) que se baseia no princípio da boa-fé objetiva".

Vale destacar que direito de informação está intimamente relacionado com o princípio da boa-fé objetiva, dada sua íntima correção com o princípio da informação, transparência e confiança. Na esteira do pensamento de Gonçalves $(2008$, p. 53) "a consideração da complexidade da realidade material, a par dos formalismos linguísticos, bem como a possibilidade de rever o contrato com base na alteração das circunstancias", objetivam assegurar a igualdade entre os pares, nas hipóteses em que contingencias futuras tornariam desigual exigir o estrito cumprimento do pactuado, sendo estas vivências jurídicas possibilitadas pela boa-fé e por ela justificadas.

Ainda segundo a autora (2008, p. 54), o conceito de solidariedade envolve a ideia de confiança, embora com ela não se confunda, já que a co-responsabilidade pelos ônus e vantagens, essencial para a ideia de solidariedade, não se inclui na ideia de confiança, compreendida como expectativa mútua de que nenhuma parte explorará a vulnerabilidade da outra numa troca, envolvendo a ideia da não-exploração.

A informação clara e precisa, portanto, visa garantir os direitos básicos dos consumidores, como a qualidade dos produtos e serviços oferecidos no mercado de consumo, além da proteção 
contra os riscos à saúde ou segurança (exceto, obviamente, os considerados normais e previsíveis por sua natureza e fruição, consoante estabelece o artigo $8^{\text {o1 }}$ da Lei 8.078/90).

Porém, a informação adequada e clara, como estabelece o artigo $6^{\circ}$, inciso III do CDC nem sempre é de fácil compreensão ao chamado homem médio, principalmente quando traz em seu bojo expressões pouco usuais, a exemplo de palavras técnicas de difícil entendimento, salvo para os conhecedores de suas respectivas áreas, considerando a existência de uma grande diversidade de especialidades no universo das profissões.

O STJ, em julgamento do EREsp 1.515.895-MS, assentou entendimento de que "o direito à informação está relacionado com a liberdade de escolha do consumidor e vinculado à correta, fidedigna e satisfatória informação do fornecedor sobre os produtos e serviços postos no mercado", de onde se conclui que deriva do respeito aos direitos básicos do consumidor, que o preveem como essencial. Importante frisar também que o direito à informação é corolário do princípio da confiança. Quando a informação é fidedigna desperta segurança, sendo esta a sua utilidade para concretizar o direito de escolha do consumidor e a satisfação da sua justa expectativa.

Apesar de o Direito procurar acompanhar o desenvolvimento da sociedade, estará sempre regulando na medida em que forem surgindo tal necessidade. Há previsão legal para o direito à informação adequada e clara, e como tal deve ser passada ao consumidor de todo e qualquer produto ou serviço. A natureza predominantemente principiológica do CDC vem proporcionando importantes inovações para o universo jurídico brasileiro, buscando a efetivação da justiça social, proibindo ou limitando certas práticas de consumo e acompanhando, dentro do possível, o desenvolvimento célere da sociedade de riscos.

Ao se discorrer acerca da tutela constitucional aos consumidores, como direito e garantia fundamental, não se pode perder de vista que o direito à informação deve ser entendido como uma tutela coletiva em busca da proteção de toda a sociedade. Independentemente de determinados direitos serem compreendidos como direitos fundamentais ou como deveres legais fundamentais, aos direitos dos consumidores sempre corresponderão os deveres dos fornecedores, e a outorga de direitos não significa ignorar os deveres, por isso a informação é um importante instrumento para garantir-se exercitá-los.

Estamos caminhando para encontrar as melhores soluções na esfera jurídica em busca da garantia dos direitos sociais, entre o quais o direito à informação é um dos mais importantes, haja vista que o consumidor bem informado está capacitado a fazer escolhas acertadas, de acordo com as necessidades e desejos individuais.

\section{VULNERABILIDADE GERAL PRESUMIDA E A HIPERVULNERABILI- DADE INCERTA DO NANOCONSUMIDOR}

A doutrina estrangeira tem se debruçado sobre a reflexão do tema concernente às relações de consumo e a nanotecnologia. Na esteira do pensamento de Sass (2007, p. 2-9), entende-se que apesar do potencial incrível dos nanomateriais para o desenvolvimento de tecnologias limpas e seguras, a informação mais recente indica o grave potencial desses componentes resultarem em danos à saúde humana e aos sistemas ecológicos. Os materiais em nanoescala tem atualmente uma grande capilaridade comercial.

1 Art. $8^{\circ}$ Os produtos e serviços colocados no mercado de consumo não acarretarão riscos à saúde ou segurança dos consumidores, exceto os considerados normais e previsíveis em decorrência de sua natureza e fruição, obrigando-se os fornecedores, em qualquer hipótese, a dar as informações necessárias e adequadas a seu respeito. 
Corroborando tais conceitos atinentes à insegurança informacional e a imprevisibilidade dos efeitos à saúde humana decorrentes do consumo de bens compostos de nanopartículas, Trancoso (2010, p. 205-222), trazendo outra ilação da doutrina estrangeira, é enfática ao dizer que existe uma aproximação com o princípio da precaução, dada a situação de incerteza a respeito da existência de um risco de dano grave e irreversível à saúde pública e para a alimentação. Na opinião da referida autora, a admissão de uma culpa por precaução contribuirá para incrementar os deveres impostos aos profissionais por suas atividades e pelos produtos que fabricam. Incumbiria aos produtores que se encontram em posição de dúvida a respeito dos efeitos do uso de seus produtos ou técnicas, tomar as medidas a fim de prevenir a realização de ameaças à saúde.

Ao tratar da regulação da nanotecnologia e sua regulação, Ludlow (2007, p. 177-203) pontua em relação ao tema da rotulagem e da livre escolha do consumidor, que é possível que o player fraco da relação tenha preocupações com os nano-alimentos, principalmente com relação à segurança de tais alimentos e produtos. Segundo a autora, a Royal Society do Reino Unido e o Instituto Britânico de Ciência e Tecnologia de Alimentos recomendaram que os nanomateriais sejam declarados como tais nos rótulos dos alimentos, tentando (ainda que de modo precário) mitigar (ou melhor, publicizar) os prováveis riscos no caso concreto.

A vulnerabilidade é o fator que representa todo o rol de particularidades do consumidor, permitindo-se compreender porque o mesmo se mostra enfraquecido diante do fornecedor, bem como diante dos riscos que compõe o contexto econômico e social designado de mercado de consumo. A presunção de vulnerabilidade do consumidor é um dos princípios gerais do artigo $4^{\circ}$, inciso I, do CDC, e visa à correta interpretação e aplicação das regras que a regulam. É uma presunção legal absoluta que, segundo Miragem (2014, p. 122), informa se as normas do direito do consumidor devem ser aplicadas e como devem ser aplicadas, associando-se à noção de fraqueza de um dos sujeitos da relação jurídica.

Essa fragilidade pode ser determinada pelas condições ou qualidades do próprio sujeito ou de uma condição de força do outro sujeito da relação. Não sendo possível essa verificação in concreto, optou o legislador por estabelecer que todos os consumidores são vulneráveis por via da presunção.

A vulnerabilidade é o marco que caracteriza a relação de consumo e o que justifica a criação de regras de proteção ao ente reconhecidamente mais frágil, que passa por contratações marcadas pela desigualdade de forças, gerando o desequilíbrio da relação. Por essa razão, o microssistema criado pelo CDC buscou reestabelecer o equilíbrio a fim de compensar a fragilidade de uma das partes, reequilibrando a situação fática e jurídica.

A condição de vulnerabilidade do consumidor pode ser considerada também de acordo com o estado da pessoa, podendo ser permanente ou provisória, individual ou coletiva, que fragiliza o sujeito de direitos, desequilibrando a relação. A fragilidade do consumidor ante o fornecedor existe por se encontrar sempre em desvantagem técnica e econômica, tolhido em sua liberdade, eis que preso às necessidades cotidianas e atormentado pela influência da mídia. Ademais, o consumidor não dispõe de controle sobre os bens de produção e, sem dúvida, é vulnerável porque não tem o controle do mercado quanto ao que se produz e como se produz.

Atualmente, há consenso acerca da vulnerabilidade do consumidor. Pode-se dizer que em todos os países do mundo ocidental capitalista há este reconhecimento, havendo previsão no artigo $1^{\circ}$ da Resolução n. ${ }^{\circ} 39$ da ONU sobre os direitos do consumidor. A vulnerabilidade do consumidor é reconhecida sob o ponto de vista jurídica, fática, informacional ou técnica, sendo necessário o aprofundamento apenas destas duas últimas como foco da nossa pesquisa. 
Sob o aspecto jurídico consiste na falta de conhecimentos jurídicos específicos. No viés fático (socioeconômico), deve ser entendida como a superioridade do fornecedor, que pode decorrer de seu poder econômico ou, ainda, da essencialidade do serviço que presta. Quanto ao caráter informacional, não decorre da falta de informação, mas da sua desqualificação. Em relação ao aspecto técnico, trata-se de um desconhecimento específico do consumidor em relação ao objeto adquirido. A vulnerabilidade pode, além disso, ser agravada em virtude de vários fatores. Dizem Pasqualoto e Soares (2017, p. 81-109) que:

\begin{abstract}
Segundo os 'autores do anteprojeto da Lei 8078/1990, a vulnerabilidade do consumidor surge a partir do reconhecimento de uma condição de inferioridade do consumidor diante do fornecedor, pois este detém os meios de produção e pode controlar o mercado, provocando uma situação de relativa passividade do consumidor, o que justificaria a implementação de regras jurídicas protetivas específicas que favorecessem a tutela dos interesses desses, notadamente quando exercidos em juízo’.
\end{abstract}

Certamente, o simples ato de ir à padaria para comprar um pão já demonstra o grau de vulnerabilidade do consumidor, considerando que não tem nenhuma ingerência na fabricação do referido alimento. Outro exemplo é quando busca um transporte aéreo, pois não tem qualquer conhecimento quanto ao manuseio da aeronave, ao treinamento do piloto e dos tripulantes e, menos ainda, à fabricação do avião. Portanto, como lecionam os citados autores, o fornecedor é quem controla o mercado, e a relação do consumidor é passiva.

No entanto, existem consumidores ainda mais vulneráveis no mercado de consumo, por suas condições pessoais, relacionada com aspectos biológicos, sociais, vinculados ao próprio consumo, e os geográficos. A hipervulnerabilidade ainda pode se apresentar em relação aos fatores sociais (como as condições financeiras do consumidor) e à formação educacional (como a pouca instrução ou analfabetismo). Pode-se citar, ademais, os vinculados ao próprio consumo (caso do consumidor dependente químico por efeito colateral por uso de fármacos) ou, ainda, a época da formação do vínculo de consumo, ou seja, quando o produto é adquirido em tempo de escassez, enchente etc. Em relação ao fator geográfico, há hipervulnerabilidade a depender da distância ou proximidade entre consumidor e fornecedor. Registre-se que tais fatores não devem ser sempre analisados de forma isolada. Um idoso e analfabeto é hipervulnerável, porém não o é um idoso capacitado e atualizado.

Acerca da chamada hipervulnerabilidade, a doutrina de Schmitt (2014, p. 219) é esclarecedora ao lecionar que "resulta da vulnerabilidade intrínseca do consumidor, com a fragilidade que atinge determinados indivíduos". Destaca, ainda, que "merecem destaque o consumidoranalfabeto, a quem, potencialmente, pende a falta de possibilidade de pleno acesso a informações sobre os negócios entabulados, bem como o consumidor-doente", cuja debilidade física o deixa em situação desprivilegiada face à eventual discussão contratual.

O uso do termo "hipervulneráveis" ficou demarcado sobretudo a partir do julgamento pelo STJ, por conduto do Recurso Especial no 586.316-MG (julgado de 19.03.2009), onde foi reconhecido o dever de informação qualificado, relativamente a produtos contendo glúten, substância prejudicial aos portadores de doença celíaca. Existem estudos que indicam os riscos à saúde do ser humano e ao meio ambiente tendo em vista não existir ainda segurança na utilização de produtos dessa natureza. Uma série de produtos disponíveis no mercado consumidor (que vão desde vestuário a alimentação) ainda estão em fase de testes de toxicidade:

Isso significa que existem, até então, incertezas sobre a segurança desses materiais para a saúde humana e o ambiente. [...] No mercado consumidor, esses pequenos elementos dividem opiniões. Por um lado, seus atrativos: a nanotecnologia requer menos insumos, apresenta menor custo de produção, desenvolve produtos mais duráveis, flexíveis e leves. Por outro, os perigos invisíveis: 'os efeitos prejudiciais à saúde e ao ambiente ainda são pouco conhecidos', pontua o professor. 'Não se sabe e se torce para que não haja efeitos tóxicos' (BORJES, 2014). 
Em vista da norma consumerista, os produtos podem até acarretar riscos à saúde e à segurança dos consumidores, desde que normais e previsíveis (periculosidade latente ou inerente), e quando se tratar de produto fabricado, as informações devem ser fornecidas por meio de impressos que acompanham o produto, conforme dita o parágrafo único do artigo $8^{\circ}$ do $\mathrm{CDC}-\mathrm{e}$ na hipótese o fornecedor obriga-se a informar adequadamente a esse respeito.

Mas, em relação a produtos fabricados a partir de nanopartículas, por ainda não existirem estudos científicos apontando os possíveis riscos, os quais não poderiam estar no mercado de consumo, mas já estão e, portanto, além do desrespeito à norma, confere aos consumidores em geral a condição de hipervulneráveis sem qualquer categoria específica, por se encontrarem em situação de risco imprevisível frente à possibilidade de dano futuro e incerto em sua saúde e segurança, conforme examinaremos a seguir.

\title{
3. DA PROTEÇÃo À SAÚde E SEGURANÇA E A EFETIVIDAdE DA POLÍ- TICA NACIONAL DE RELAÇÕES DE CONSUMO
}

Inaugura-se o presente tópico esclarecendo de modo inequívoco que a expressão hipervulnerabilidade nas relações de consumo se identifica com a vulnerabilidade informacional agravada ou potencializada, muito peculiar no trato da publicidade infantil, na dinâmica contratual com determinada categoria de idosos, no comércio eletrônico e, no presente estudo, com a comercialização de produtos à base de nanotecnologia.

Conforme anteriormente estudado, por exigência do CDC, os produtos e serviços colocados no mercado de consumo não poderão acarretar riscos à saúde ou segurança dos consumidores. Ou seja, o legislador veda a comercialização de qualquer produto que enseje algum tipo de risco e quando estes existem, normais e previsíveis por sua natureza, o fornecedor é obrigado a informar adequadamente a esse respeito.

Entre os direitos fundamentais e universais do consumidor, reconhecidos pela ONU (Resolução 32, de 10.4.1985) consta o direito à informação, sendo de notar que o artigo 205 da CF/ 88 dispõe que a educação é "direito de todos" e visa proporcionar aos educandos o "preparo para o exercício da cidadania". No plano constitucional, a educação foi definida como o direito subjetivo de todo brasileiro cuja obrigação está diluída no Estado e na família, com a colaboração da sociedade. No campo das relações de consumo, o artigo $6^{\circ}$, inciso II, do CDC, não afastou esta obrigação também dos fornecedores como provedores de conhecimento.

Esclarecem a temática relacionada com a nanotecnologia e as relações de consumo. Engelmann e Mafaldo (2015, p. 88), que ao abordar especificamente os nanocosméticos e o direito à informação é enfático:

\begin{abstract}
A regulação das nanotecnologias tem como pressuposto dois argumentos chave: 1) as evidências científicas indicando que nanomateriais podem apresentar uma toxicidade para a saúde humana e/ou o meio ambiente diferente daquela apresentada pelos mesmos materiais em tamanho maior; 2) para poder comercializar em um mundo globalizado e em crescente liberalização econômica, torna-se necessário homogeneizar a normatização dos produtos. No contexto internacional a discussão sobre regulação e de proliferação de documentos produzidos pelas mais diversas entidades científicas, regulatórias e de normas técnicas é intensa.
\end{abstract}

Convém não confundir, porém, o dever de informar com o direito de informação, inserto em um processo formal e contínuo, primariamente de incumbência do Estado, mas não apenas a ele. A normalidade e a previsibilidade decorrem da própria natureza dos produtos e serviços, pois, caso contrário, não poderiam ser inseridos no mercado, uma vez que todos, de alguma 
maneira, apresentam algum grau de risco à saúde e à segurança dos consumidores. Ocorre que "todo o produto ou serviço, por mais seguro e inofensivo, traz sempre um pouco de insegurança para o consumidor" (GARCIA, 2016, p. 144). Assim, o referido autor defende que a insegurança somente poderá ser avaliada casuisticamente e de acordo com a justa expectativa do consumidor (o qual deve ser devidamente informado, de maneira ostensiva e adequada, sobre a periculosidade ou nocividade do que deseja adquirir).

As empresas da atualidade, até por necessidade de redução de insumos e consequente preservação da natureza, buscam melhores condições para a produção de bens e investem na pesquisa sobre novas energias através de matérias-primas e tecnologias mais avançadas (tais como a biotecnologia, microinformática, nanotecnologia, fibra ótica, energias renováveis).

Em relação à Secretaria Nacional do Consumidor (SENACON), órgão integrante do Ministério da Justiça, com atribuição de promover a Política Nacional das Relações de Consumo, tem-se que conforme artigo $4^{\circ}$, inciso II, alínea "d" do mesmo CDC, objetiva-se atender às necessidades dos consumidores, o respeito à sua dignidade, saúde e segurança, com ações governamentais que protejam o consumidor a partir da garantia dos produtos e serviços com padrões adequados de qualidade, segurança, durabilidade e desempenho, porém, sem alusão aos produtos industrializados a partir da nanotecnologia.

A par disso, Borges e Martins (2017, p. 427) afirmam que os produtos à base de nanotecnologia estão chegando silenciosamente ao mercado e, ao que tudo indica, carecem os consumidores de informações sobre quantos e quais produtos se utilizam da tecnologia de nanopartículas, sobretudo em relação ao potencial dos efeitos anunciados, toxinas, todos capazes de afetar as impositivas relações entre o meio ambiente e a saúde dos seres humanos.

\section{CONCLUSÃo}

Conforme visto no decorrer do presente trabalho, os riscos em relação ao uso de nanopartículas ainda são indefinidos, situação própria de uma sociedade complexa, porque a cada dia que se passa surgem novidades no campo científico e tecnológico. Tanto os cientistas quanto os fornecedores desconhecem os riscos de sua utilização. A nanotecnologia é considerada de ponta porque reduz os custos de insumos para a fabricação dos produtos, diminuindo, em tese, os desgastes naturais, o que se torna uma técnica muito bem-vinda, para se evitar a retirada de matéria prima da natureza. No entanto, com a indefinição da ciência nanotecnológica e a imprecisão das informações prestadas ao fornecedor, o direito à informação encontra-se, teoricamente, comprometido, já que dificulta aos fornecedores o cumprimento do dever de informação clara e objetiva nos termos da lei consumerista e consequentemente, prejudica o direito à informação do consumidor.

Foram expostas algumas indagações centrais sobre o desenvolvimento das nanotecnologias e as relações de consumo no início do presente estudo, os quais pretende-se responder de forma a contribuir com a ciência do direito. Recapitulando agora conclusivamente: estaria o destinatário final destes produtos suficientemente informado de suas consequências? Em que se diferencia o consumidor em geral daquele que consome bens contendo nanotecnologias (existe uma agudização de sua vulnerabilidade apriorística)? Qual o fundamento teórico para basear uma eventual responsabilização do fornecedor por danos imprevistos causados ao nanoconsumidor?

Em resposta às problematizações em epígrafe, tem-se que o consumidor não está suficientemente informado das consequências para a sua saúde no manejo de produtos fabricados à 
base de nanopartículas, inserindo-o numa condição de especial vulnerabilidade, dada a agudização dos riscos inerentes ao contato com eventuais substâncias potencialmente tóxicas inclusive. A nanopartícula também pode desencadear desequilíbrios ambientais, o que torna ainda mais difícil a previsão dos riscos. Neste passo, a insuficiência de informações nanotecnológicas capazes de demonstrar com precisão os riscos que os consumidores correm em contato com os produtos desenvolvidos, apresenta contornos de uma nova espécie de hipervulnerabilidade.

Entende-se que incumbiria aos produtores que se encontram em posição de dúvida a respeito dos efeitos do uso de seus produtos ou técnicas, tomar as medidas cabíveis a fim de prevenir eventuais ameaças à saúde, informando ao consumidor que as consequências de sua manipulação ainda não foram definidas pela ciência. A título de sugestão, entende-se que o dever de informação poderá ser mitigado se admitida, por precaução, uma advertência, a exemplo do símbolo de produtos transgênicos, com a informação "consequências desconhecidas por sua manipulação" facilitando o cumprimento dos deveres impostos aos profissionais por suas atividades e pelos produtos que fabricam. Somente a ausência desse alerta ao consumidor, poderia caracterizar responsabilidade do fornecedor.

Por fim, ante a ausência de informações claras e objetivas (patrimônio fundamental do player fraco das relações consumeristas) quanto aos possíveis riscos à saúde e à segurança do consumidor de produtos industrializados a partir de nanopartículas, conclui-se pela probabilidade de dano coletivo, que se traduz como novo pressuposto epistemológico da ciência pósmoderna, cuja causalidade dos fatos não é linear, ensejando múltiplos e imprevisíveis vetores consequenciais, com infringência ao artigo $8^{\circ}$ da Lei 8.078/90. Ademais, o consumidor em geral que adquire produtos sujeitos à base da nanotecnologia encontram-se em situação de hipervulnerabilidade, haja vista que a ausência de esclarecimentos é qualificada e a sua condição de fragilidade se agudiza pelo fato de conviver com bens de consumo sobre cuja incerteza ontológica em relação à composição, toxidade e suas consequências não se pode mensurar.

\section{REFERÊNCIAS}

BECK, Ulrich. Sociedade do risco: rumo a uma outra modernidade (tradução de Sebastião Nascimento), São Paulo: Editora 34, 2011.

BITTAR, Eduardo Carlos. O Direito na pós-modernidade, 3. ed, São Paulo: Atlas, 2014.

BORGES, Gustavo Silveira; MARTINS, Patrícia Santos. As nanotecnologias, os riscos incertos e a hipervulnerabilidade do nanoconsumidor. Revista de Direito do Consumidor, v. 113, ano 26, p. 417-438. São Paulo: Revista dos Tribunais, set-out/2017.

BORJES, Isabel Cristina Porto. Responsabilidade civil e nanotecnologias. São Paulo: Atlas, 2014.

BRASIL. Constituição da República Federativa do Brasil de 1988. Disponível em: http://www.planalto.gov.br/ccivil_03/constituicao/constituicao.htm. Acesso em: 28 de nov. 2019.

BRASIL. Lei n..$^{\circ} 8.078$ de 11 de setembro de 1990. Dispõe sobre a proteção do consumidor e dá outras providências. Disponível em: http://www.planalto.gov.br/ccivil_03/leis/18078.htm. Acesso em: 29 de nov. 2019.

BRASIL, Superior Tribunal de Justiça. Recurso Especial. REsp 1.358.615-SP. 4. ${ }^{\text {a }}$ Turma. Brasília: DF, Relator: Ministro Luis Felipe Salomão, DJ: 02.05.2013, Jusbrasil 2013, Acesso em 15 de nov. 2019. Disponível em www.stj.jus.br. 
BRASIL, Superior Tribunal de Justiça. Embargos de Declaração em Resp. EREsp 1.515.895MS. Brasília: DF. Relator: Ministro Humberto Martins. DJ: 20.09.2017. Jusbrasil 2017, Acesso em 15 de nov. 2019. Disponível em www.stj.jus.br.

BRASIL, Superior Tribunal de Justiça. Recurso Especial. Resp. 586.316-MG. Brasília: DF, Relator: Herman Benjamim, DJ: 19.03.2009. Jusbrasil 2009, Acesso em 15 de nov. 2019. Disponível em www.stj.jus.br.

ENGELMANN, Wilson; MAFALDO, Camila. Nanorregulação: condições e possibilidades para a sua estruturação. In: ENGELMANN, Wilson (org) Nanocosméticos e o Direito à Informação. Deviant: RS, 2015. Disponível em: https://www.editoradeviant.com.br/wp-content/uploads/woocommerce_uploads/2017/03/Nanocosmeticos-e-o-Direito-a-Informacao.pdf. Acesso em: 27 de nov. 2019.

FREITAS, Osmar. Os riscos da nanotecnologia. Cientistas alertam sobre possíveis efeitos nocivos de produtos que usam partículas microscópicas, como filtros solares e cremes. Revista Época, ed. n. ${ }^{\circ}$ 484, ago./2017. Disponível em: http://revistaepoca. globo.com/ Revista/Epoca/ 0,,EDG78783-6010,00-OS+RISCOS+DA+NANSANTOS,NANOTECNOLOGIA.html.

Acesso em:4 de dez.2018

GARCIA, Leonardo de Medeiros. Código de Defesa do Consumidor Comentado: artigo por artigo. 12a edição, Salvador: JusPodium, 2016.

GONÇALVES, Camila de Jesus Mello. Princípio da boa-fé: perspectivas e aplicações. Rio de Janeiro: Elsevier, 2008.

LIPOVETSKY, Gilles. A felicidade paradoxal: ensaio sobre a sociedade do hiperconsumo. Lisboa: Edições 70, 2015.

LUDLOW, Karinne. The Readiness of Australian Food Regulation for the use Nanotechnology in Food and Food Packaging. University of Tasmania Law Review, vol. 26, Issue 2, 2007. Disponível em: http://www.austlii.edu.au/au/journals/UTasLawRw/2007/9.pdf. Acesso em: 29 de nov. 2019.

MARQUES, Claudia Lima; BENJAMIN, Antonio Hermann; MIRAGEM, Bruno. Comentários ao código de defesa do consumidor. 5.ed. rev, atual e ampl. São Paulo: Editora Revista dos Tribunais, 2016.

MARTINS, Paulo. Nanotecnologia e meio ambiente para uma sociedade sustentável. Estudios Sociales, v.17 n.34 México jul/dic.2009. Disponível em: http://www.scielo.org.mx/scielo.php?script=sci_arttext\&pid=S0188-45572009000200012. Acesso em:7 dez.2018.

MIRAGEM, Bruno. Curso de direito do consumidor. $5^{\text {a }}$ edição. São Paulo: Revista dos Tribunais, 2014.

PÁDUA, Elisabete M. M. de. Ciências sociais, complexidade e meio ambiente, Campinas: Ed. Papirus, 2008, p. 32.

PASQUALOTO, Adalberto; SOARES, Flaviana Rampazzo. Consumidor hipervulnerável: análise crítica, substrato axiológico, contornos e abrangência. Revista de Direito do Consumidor, v.113, ano 26, p. 81-109. São Paulo: Revista dos Tribunais, 2017.

PAULO, Francisco Alexandre de; CAETANO, Philippe José Maciel; GERALDO, Viviany. Aplicações da nanotecnologia na construção civil: análise experimental em argamassa expansiva com nanotubos de carbono. Pensar Engenharia, v.3, n. 1, jan./2015.Disponível em: http://revistapensar.com.br/engenharia/pasta_upload/arti gos/a152.pdf. Acesso em:15 dez.2018 
REINIG, Guilherme Henrique Lima. Riscos do desenvolvimento no Código de Defesa do Consumidor: a responsabilidade do fornecedor por defeitos não detectáveis pelo Estado dos conhecimentos científicos e técnicos. Revista de Direito do Consumidor, v. 124, ano 28, p. 343-392, São Paulo: Revista dos Tribunais, 2019.

SANTANA, Hector Valverde. Proteção internacional do consumidor: necessidade de harmonização da legislação. Revista de Direito Internacional, Brasília: DF, v.11, n.1, 2014. Disponível em: https://core.ac.uk/download/pdf/79125014.pdf. Acesso em: 29 de nov. 2019.

SASS, Jennifer. Nanotecnologies: The Promise and the Peril. Year Of Susteinable Development. Law \& Policy, vol. 7, Issue 4 (Summer 2007). Disponível em: https://digitalcommons.wcl.american.edu/sdlp/. Acesso em 29 de nov.2019.

SCHIER, Flora Margarida Clock. A boa-fé como pressuposto fundamental do dever de informar. Curitiba: Juruá, 2006.

SCHMITT, Cristiano Heineck, Consumidores hipervulneráveis: a proteção do idoso no mercado de consumo. São Paulo: Atlas, 2014.

TRANCOSO, Maria Isabel. El Principio de la Precaucion y la Responsabilidad Civil. Revista de Derecho Privado 205, vol. 18, 2010.

VASQUEZ, Júlio Sebastián Zárate; GRANADOS. Luis Romero; LLERENA, Malena Diestra. La Relacion entre el desarrollo de las nanotecnologias y la indústria cosmética en el Peru. In: ENGELMANN, Wilson (org.). Nanocosméticos e o direito à informação. Deviant: RS, 2015.

Recebido em: 18 nov. 2019.

Aceito em: 10 dez. 2019. 